\title{
The Impact of Private Equity on Corporate Performance: An Empirical Research of the Listed Companies on GEM
}

\author{
Fan Xin ${ }^{1, a}$, Wu Xiumin ${ }^{2, b, *}$ \\ ${ }^{1}$ School of Business, Sichuan Agricultural University, Chengdu, Sichuan, China \\ ${ }^{2}$ School of Business, Sichuan Agricultural University, Chengdu, Sichuan, China \\ afanxin517@163.com, ${ }^{b} 727398989 @ q q . c o m$ \\ ${ }^{*}$ Corresponding author
}

Keywords: Private Equity, Corporate Performance, Growth Enterprises Market.

\begin{abstract}
On the basis of reviewing the previous literature, this paper puts forward hypotheses through certification hypothesis, monitoring hypothesis and grandstanding hypothesis. We select listed companies on Shenzhen growth enterprise market from 2014 to 2018 as the research objects, aiming to analyze the impact of private equity on corporate performance and to further study whether the private equity industry in China has been developed in a healthy, standardized and orderly way after China formally implemented the Interim Measures on the Supervision and Management of Private Equity Funds in 2014. The research results show that private equity contributes to the improvement of the company's operating performance, and the higher the shareholding ratio of private equity, the better the corporate performance, which supports the certification hypothesis and monitoring hypothesis.
\end{abstract}

\section{Introduction}

Private Equity (PE) was first developed from the United States, driving the development of a large number of overseas high-tech companies, such as Google and Microsoft. In recent years, private equity began to breathe life into the emerging capital market in China. In particular, the formal establishment of the growth enterprise market in 2009 filled the gap in the venture investment market, improved the market access and exit mechanism, and promoted the diversified development of China's capital market. In August 2014, the Interim Measures on the Supervision and Management of Private Equity Funds was officially announced and implemented, then private equity entered a stage of benign self-regulation development. On May 11, 2019, the state council included the Interim Regulations on the Management of Private Funds into the 2019 legislative work plan, which plays a crucial role in the orderly and healthy development of the private equity industry.

As a new way of financing, private equity can not only provide financial support for the invested companies, but also optimize the corporate governance structure with its professional knowledge, improve the operation and management ability and enhance the reputation of the invested companies, thus generating good external effects, promoting its rapid development and successful listing. At present, there are two different academic views on the impact of private equity on corporate performance [1]. The certification/monitoring hypothesis holds that private equity will participate in the supervision and management of the target company as a third-party certifier, improve information disclosure, reduce the underpricing rate in initial public offerings, and improve business performance. However, the grandstanding hypothesis holds that private equity investors, in order to maintain their reputation, may push the rapid listing of original immature companies, leading to the "face change" of corporate performance immediately after the IPO, and even suffer a decline in the IPO year [2]. Therefore, this paper selects the financial data of listed companies in the growth enterprise market from 2014 to 2018 as samples, and studies the impact of private equity on corporate performance through panel data regression analysis. 


\section{Literature review}

About the impact of private equity on the company, research scholars at home and abroad based on different angles of view, selected different samples to analyze, the results can be summarized as two kinds of main views, one for the PE through its certification/monitoring role to improve the invested corporate's performance, the other for the impact of PE involvement on the corporate performance is not significant. Jain \& Kini (1995) took the financial data of 272 listed companies in the North American stock market as samples to compare the difference in the business performance of the companies with venture capital support and without venture capital support after IPO, the results showed that the companies with venture capital background performed better after IPO [3]. Nick Wilson et al. (2012) studied the performance of private equity in the UK during the financial recession and concluded that even during the global recession, companies with PE intervention can obtain higher productivity and profit margin [4]. Charlie (2013) analyzed 138 cases of leveraged buyouts in Britain and concluded that compared with enterprises without private equity, enterprises with private equity have better business performance [5]. Xiang Qun (2010) analyzed the financing structure of small and medium enterprise in the growth stage. The empirical results show that private equity can optimize corporate governance structure and improve corporate value and business performance [6]. Zhu Jing (2011) studied 233 listed companies on the growth enterprise market by empirical method, taking Tobin's Q value as corporate value index and Roe as corporate performance index. The empirical results show that private equity is positively correlated with Tobin's Q value and Roe [7]. $\mathrm{Hu}$ Yan (2017) et al. studied the influence mechanism of private equity on enterprise performance from the perspective of cash holdings and $R \& D$ investment. The research results showed that PE can increase the likelihood of enterprise R\&D investment and improve business performance at a certain level of cash holdings [8].

While Feng Ke et al. (2013) summarized the impact of PE into four kinds of models, namely, adverse selection effect, certification effect, monitoring effect and grandstanding effect, and verified whether these four effects existed in the listed companies in the growth enterprise market. The results showed that there was no significant difference between the performance of companies with PE shares and those without PE shares in the first two years of listing, that is, there was no adverse selection effect and monitoring effect [9]. Zhang Bin et al. (2013) took the data of listed companies in China's small and medium-sized board and gem as samples, then used Tobin's Q to empirically analyze the significant positive correlation between private equity and company value, which was not reflected in the gem companies, because the immaturity of gem limited the effectiveness of PE participation [10]. Zhang Yongming et al. (2018) empirically tested the impact of private equity on the IPO performance of listed companies based on the two competitive theories of certification and monitoring hypothesis and grandstanding hypothesis. The research results showed that private equity through accrual earnings management to reduce the corporate performance in the IPO year, and the conclusion supported the grandstanding hypothesis [1].

Through the review of relevant literature, it can be found that scholars have established a relatively mature research framework, but the impact of private equity on corporate performance is still not a unified conclusion. At the same time, due to the imperfect system and low availability of data, Chinese researchers mostly use sectional data so that lack of data continuity. Therefore, this paper selects listed companies on gem from 2014 to 2018 as samples to further verify whether the private equity industry in China has been standardized and healthy developed since the implementation of the Interim Regulations on the Supervision and Management of Private Equity Funds in 2014, and whether it can truly reduce the manipulation of PE and improve the corporate performance.

\section{Theoretical analysis and research hypothesis}

Megginson \& Weiss (1991) proposed the certification hypothesis by investigating the impact of private equity on IPO pricing and equity structure of companies, providing support for the certification role of private equity in the process of company listing [11]. The certification hypothesis holds that, compared with companies without PE support, the involvement of private equity investors 
can play a proving role, reduce information asymmetry, and help listed companies attract higher quality securities underwriters, auditors and institutional investors, thereby reducing the total cost of IPO listing and maximizing net income. Private equity investors usually play their certification functions and participate in the company's supervision and management as third-party certifiers or as shareholders of the invested company. For invested companies, private equity investors can make IPO pricing reasonable, improve corporate information disclosure and improve business performance. Meanwhile, the certification of private equity investors indirectly becomes the reference for institutional investors to judge the performance of target companies.

However, Gompers (1996) suggested that in order to build a reputation and prepare for the next private equity funds, some newly established private equity investment institutions would raise funds in a short period of time to help the invested enterprises go public quickly, so they put forward the grandstanding hypothesis [12]. With the incentive to grandstand, PE institutional investors will reduce the shares they hold and shorten the investment period in order to obtain a larger scale of private equity fund. In this way, immature companies will be promoted to go public in a short time with a low IPO pricing, and the corporate performance declines rapidly after IPO. Different from previous studies, the grandstanding hypothesis analyzes the negative impact of private equity intervention, which may lead to a decline in the return on capital and inconsistent with expected earnings. Therefore, the following hypothesis is proposed in this paper:

Hypothesis 1: Compared with companies without PE support, companies with PE support have better corporate performance;

Hypothesis 2: Compared with companies without PE support, companies with PE support have worse corporate performance.

Barry (1990) provided the first empirical support for the monitoring role of private equity on companies [13]. According to the monitoring hypothesis, private equity investors will focus on investing in a few industries, hold equity in the invested companies, and participate in the supervision and management of the companies with professional knowledge and industry experience. After the IPO, private equity investors will continue to hold the equity and serve as directors of the invested company, so as to improve the corporate governance structure and improve the company's performance. For the private investors with high quality, the capital market recognizes their supervisory role. The higher the shareholding ratio of private equity investors is, the more active they will be in the supervision and management of the company and play a more important role in corporate governance. Therefore, the following hypothesis is proposed in this paper:

Hypothesis 3: The higher the PE shareholding ratio, the better the corpoerate performance of the invested company.

\section{Research design}

\subsection{Sample selection and date source}

Since China resumed IPO in early 2014, this paper selects the financial data of Chinese gem listed companies from 2014 to 2018 as samples. Because the number of companies with private equity involvement varies every year, this paper selects and judges whether there is private equity firstly, then adds up the shareholding ratio and excludes companies with less than 5\% shareholding ratio, finally obtains an unbalanced panel data. The filter results are shown in Table 1. As for the judgment of whether there is private equity, firstly, read the prospectus of gem listed companies and judge whether there is PE involvement when the companies are listed. Secondly, referring to the judgment method of Wu Chaopeng et al. (2012), if the top ten shareholders' names of listed companies contain keywords such as "investment", "venture capital" and "venture capital", it can be determined as private equity [14]. If a company has more than one private equity investment institutions joint investment, the total of their shareholding ratio is the proportion of private equity.

In order to ensure the integrity of data, companies with missing financial data were eliminated. The financial data of gem listed companies, such as return on equity, return on total assets, total assets, 
asset-liability ratio, equity concentration and the names and shareholding ratios of the top ten shareholders, are all derived from CSMAR.

In this paper, Stata12.0 was used to conduct descriptive statistics and panel data regression for relevant variables.

Table 1. Sample Observations

\begin{tabular}{lccccc}
\hline & 2014 & 2015 & 2016 & 2017 & 2018 \\
\hline Whole sample observations & 417 & 497 & 602 & 718 & 736 \\
PE sample observations & 240 & 276 & 343 & 416 & 427 \\
PE proportion & $57.55 \%$ & $55.53 \%$ & $56.98 \%$ & $57.94 \%$ & $58.01 \%$ \\
\hline
\end{tabular}

\subsection{Variable definition and regression model}

\subsubsection{Explained variables}

This paper refers to Liu Yuanyuan (2011), who selected return on equity and return on total assets as a measure of corporate performance indicators. Return on equity (Roe) is the percentage ratio of a company's after-tax profit divided by its net assets, which can reflect the return level of shareholders' equity and measure the efficiency of using free capital. The higher the roe, the higher the return on investment, the better the company's operating performance. In order to improve robustness, this paper selects return on total assets (Roa) as an another indicator to measure corporate performance. Return on total assets is the ratio of a company's net profit to its average total assets.

\subsubsection{Explanatory variables}

The explanatory variables in this paper are PE dummy variable and PE shareholding ratio. As for PE dummy variable, if there is private equity investment, the value is 1 ; otherwise the value is 0 . PE shareholding ratio variables refer to the method of Liu Yuanyuan et al. (2011) and Wu Chaopeng (2012), judge whether they are private equity investment institutions by the names of the top 10 shareholders of gem companies and IPO prospectuses. Finally, PE shareholding ratio can be obtained by adding the shareholding ratios of various private equity investment institutions.

\subsubsection{Control variables}

At the same time, this paper selects the total assets, asset-liability ratio and ownership concentration as control variable, which also have a certain impact on the corporate performance.

Table 2. Variable definition and description

\begin{tabular}{lllc}
\hline Variable type & Variable definition & Symbol & Variable description \\
\hline \multirow{2}{*}{ Explained variables } & Return on equity & ROE & Net profit / Net asset \\
\cline { 2 - 4 } & Return on total assets & ROA & Net profit / Average Total assets \\
\hline \multirow{2}{*}{ Explanatory variables } & PE dummy variable & PE & If have PE, value 1; otherwise value 0 \\
\cline { 2 - 4 } & PE shareholding ratio & PEshare & Private equity shareholding ratio \\
\hline \multirow{2}{*}{ Control variables } & Size of company & Size & Natural logarithm of total assets \\
\cline { 2 - 4 } & Asset-liability ratio & Leverage & Total liabilities / Total assets \\
\cline { 2 - 4 } & $\begin{array}{l}\text { Ownership } \\
\text { concentration }\end{array}$ & Shrcr & $\begin{array}{c}\text { The sum of the shareholding ratio of the } \\
\text { top 5 shareholders }\end{array}$ \\
\hline
\end{tabular}

\subsubsection{Explained variables}

According to the research hypothesis, the following model is established in this paper:

$$
\begin{aligned}
& \operatorname{ROE}(\mathrm{ROA})=\alpha+\beta_{1} \mathrm{PE}+\beta_{2} \text { Size }+\beta_{3} \text { Leverage }+\beta_{4} \text { Shrcr }+\varepsilon_{\text {it }} \\
& \operatorname{ROE}(\mathrm{ROA})=\alpha+\beta_{1} \text { PEshare }+\beta_{2} \text { Size }+\beta_{3} \text { Leverage }+\beta_{4} \text { Shrcr }+\varepsilon_{\text {it }} .
\end{aligned}
$$


Model (1) is used to test $\mathrm{H} 1$ and $\mathrm{H} 2$, that is, the influence of private equity on corporate performance; Model (2) is used to test $\mathrm{H} 3$, that is, the higher the shareholding ratio of private equity, the better the company performance.

\section{Empirical analysis and conclusions}

\subsection{Descriptive statistical analysis}

Table 3 and Table 4 reports the descriptive statistics for main variables. As can be seen from table 3 , the minimum Roe value of whole sample is $-679.7 \%$, the maximum value is $60.4 \%$, and the average value is $6.9 \%$. The minimum Roa value of whole samples is $-185.9 \%$, the maximum value is $46.6 \%$, the average value is $5.2 \%$, and the standard deviation is 0.091 , which indicates that there is a certain degree of difference in corporate performance and efficiency of using own capital. From the perspective of the size of the companies, the minimum value of the whole sample is 18.961 , the maximum value is 25.026 , and the standard deviation is 0.853 , indicating that there is a small difference in the size of listed companies in the growth enterprise market. Leverage has a minimum value of $1.4 \%$, a maximum value of $168.7 \%$, and the average value is $31.7 \%$, indicating that different companies have different solvency and debt management capabilities. Some companies have a high financial leverage, indicating that the company has a large amount of debt, which may not be conducive to the company's business performance in the long run.

Table 4 is the descriptive statistical table of the private equity sample. The average Roe value of PE sample is $7.8 \%$ and Roa value is $5.8 \%$, both of which are higher than the average value of the whole sample. It can be preliminarily speculated that the participation of private equity can appropriately improve the company performance and income level. As can be seen from the table 4, the maximum value of shareholding ratio of private equity is $89.730 \%$, and the average value is $21.372 \%$, indicating that most companies tend to introduce private equity, and the shareholding ratio is relatively high.

Table 3. Descriptive statistics of the whole sample

\begin{tabular}{cccccc}
\hline Variable & Observations & Minimum & Maximum & Mean & Standard deviation \\
\hline Roe & 2970 & -6.797 & 0.604 & 0.069 & 0.220 \\
Roa & 2970 & -1.859 & 0.466 & 0.052 & 0.091 \\
PE & 2970 & 0 & 1 & 0.495 & 0.573 \\
Size & 2970 & 18.961 & 25.026 & 21.325 & 0.853 \\
Leverage & 2970 & 0.014 & 1.687 & 0.317 & 0.173 \\
Shrcr & 2970 & 7.286 & 90.143 & 53.554 & 12.641 \\
\hline
\end{tabular}

Table 4. Descriptive statistics of the PE sample

\begin{tabular}{cccccc}
\hline Variable & Observations & Minimum & Maximum & Mean & Standard deviation \\
\hline Roe & 1702 & -6.797 & 0.604 & 0.078 & 0.227 \\
Roa & 1702 & -1.859 & 0.373 & 0.058 & 0.091 \\
PEshare & 1702 & 5.000 & 89.730 & 21.372 & 16.467 \\
Size & 1702 & 18.961 & 25.026 & 21.306 & 0.859 \\
Leverage & 1702 & 0.027 & 0.989 & 0.322 & 0.167 \\
Shrcr & 1702 & 17.119 & 90.143 & 55.252 & 12.780 \\
\hline
\end{tabular}

\subsection{Empirical analysis of Private Equity on the Corporate Performance}

In order to test Hypothesis 1 and Hypothesis 2, Roe and Roa are respectively taken as explained variables and PE dummy variables as explanatory variables while controlling size, leverage and shrcr 
for the regression of model (1). The regression results are shown in Table 5. It can be seen from the Table 5 that Roe is positively correlated with PE dummy at the significance level of 5\% with a correlation coefficient of 0.014 . At the same time, Roa is positively correlated with PE dummy at the significance level of $1 \%$ with a correlation coefficient of 0.010 , which indicating that private equity can improve the corporate performance. Therefore, Hypothesis 1 in this paper is verified and $\mathrm{H} 2$ is rejected simultaneously. The empirical results support the certification hypothesis, showing that private equity institutions can play a certification role in the supervision and management of the company, reduce market information asymmetry, attract higher quality securities underwriters and institutional investors to increase their investment in the company, so as to improve corporate performance.

In addition, the size of company is positively correlated with Roe at the significance level of $1 \%$, indicating that the expansion of company size is conducive to the improvement of corporate performance. There is a significant negative correlation between asset-liability and Roe at the significance level of $1 \%$, contrary to the previous conclusions hold that certain asset-liability ratio can improve corporate performance. Thus, we can come to a conclusion that companies should take appropriate liabilities and make rational use of the borrowed funds. When the explained variable is ROA, the regression results are still robust.

Table 5. Regression result of Model (1)

\begin{tabular}{ccc}
\hline & Roe & Roa \\
\hline PE & $0.014^{* *}$ & $0.010^{* * *}$ \\
Size & $0.027^{* * *}$ & $0.012^{* * *}$ \\
Leverage & $-0.299^{* * *}$ & $-0.177^{* * *}$ \\
Shrcr & $0.003^{* * *}$ & $0.003^{* * *}$ \\
Adj- $\mathrm{R}^{2}$ & 0.462 & 0.524 \\
$\mathrm{~F}$ & 66.38 & 133.30 \\
\hline
\end{tabular}

Note: $* * * * *$, and $*$ indicate significant levels at $1 \%, 5 \%$, and $10 \%$, respectively.

In order to test Hypothesis 3, Roe and Roa are respectively taken as explained variables, PE shareholding ratio is taken as explained variables, at the same time control size, leverage and shrcr. The regression results of model (2) are shown in table 6. The coefficients of Roe, Roa and PE shareholding ratio are 0.013 and 0.017 respectively. Roe is positively correlated with the shareholding ratio of private equity at the significance level of $10 \%$ and Roa is positively correlated with the shareholding ratio of private equity at the significance level of $5 \%$, indicating that the higher the shareholding ratio of private equity is, the better the corporate performance will be. Hence, the Hypothesis 3 of this paper is established, which supports the supervision hypothesis, proving that the private equity investors play their role of supervision, hold concentrated shares in companies, serve on the board of directors and participate in corporate decisions, so as to improve the company's performance.

In addition, in the PE sample, the size of company is positively correlated with Roe at the significance level of $5 \%$, and asset-liability ratio is negatively correlated with Roe at the significance level of $1 \%$. From the perspective of ownership concentration, shrcr is positively correlated with Roe at the significance level of $1 \%$, which to some extent indicates that the concentrated shareholding of private equity institutions is conducive to improving corporate performance. When the explained variable is Roa, except that the positive correlation between company size and Roa is not significant, other results are still robust. 
Table 6. Regression result of Model (2)

\begin{tabular}{ccc}
\hline & ROE & ROA \\
\hline PEshare & $0.013^{*}$ & $0.017^{* *}$ \\
Size & $0.029^{* *}$ & 0.002 \\
Leverage & $-0.291^{* * *}$ & $-0.152^{* * *}$ \\
Shrcr & $0.002^{* * *}$ & $0.002^{* * *}$ \\
Adj-R ${ }^{2}$ & 0.305 & 0.327 \\
F & 80.38 & 138.47 \\
\hline
\end{tabular}

Note: $* * *, * *$, and $*$ indicate significant levels at $1 \%, 5 \%$, and $10 \%$, respectively.

\section{Conclusion}

Based on the review of previous literature, this paper proposes the research hypothesis through the certification hypothesis, monitoring hypothesis and grandstanding hypothesis, aiming to research whether the implementation of the Interim Measures for the Supervision and Management of Private Equity Funds in 2014 has effectively improved China's private equity industry and played a beneficial role in the standard development of private equity investment. Due to the inconsistency of previous research results and imperfect data, this paper selects the listed companies in the growth enterprise market from 2014 to 2018 as research objects and conducts empirical analysis with unbalanced panel data. The results show that private equity can improve the corporate performance, and the higher the proportion of private equity $\mathrm{t}$, the better the corporate performance.

On May 11, 2019, the state council officially included the Interim Regulations on the Management of Private Equity Funds into the 2019 legislative work plan, indicating that the role of the private equity industry in China's capital market cannot be ignored, and its healthy and orderly development is also crucial. For the private equity $t$ industry, it is necessary to regulate private equity institutions, clarify the responsibilities and legal responsibilities of private equity fund managers and custodians, so as to avoid irregularities. For the companies, private equity can be appropriately introduced to improve the company's operation and management, reduce information asymmetry, and help its successful IPO.

\section{References}

[1] Y. M. Zhang, P. Pan, and D. Chao, Influence of private equity investment Entry on companies' performance in the year of IPO, Journal of Management Science, vol 31, pp. 149-160, 2018.

[2] Y. Xiong, J. Yang, Authenticating, transmission or governance? Media coverage and IPO performance change, Finance \& Trade Economics, vol.38, pp. 66-29, 2017.

[3] B. A. Jain and O. Kini, Venture capitalist participation and the post-issue operating performance of IPO firms, Managerial and Decision Economics, vol.16, pp. 593-606, 1995.

[4] N. Wilson, M. Wright, D. S. Siegel, and L. Scholes, Private equity portfolio company performance during the global recession, Journal of Corporate Finance, vol.18, pp. 193-205, 2012.

[5] C. Weir, P. Jones, and M. Wright, Public to private transactions, private equity and performance in the UK: an empirical analysis of the impact of going private, Journal of Management and Governance, vol.19, pp. 91-112, 2013. 
[6] Q. Xiang, The influence of private equity investment on growth companies -- an empirical study based on small and medium-sized listed companies, Journal of Finance and Economics, vol.16, pp. 50-54, 2010.

[7] J. Zhu, Empirical study on the relationship of private equity and firms' value -- empirical evidence based on listed Companies of small and medium board, Accounting and Finance, vol.02, pp. 20-24, 2011.

[8] Y. Hu and J. Yuan, The conduction path of private equity to affect business performance: an empirical study on the perspective of cash holdings, and R\&D Investment, Financial Economics Research, vol.32, pp. 107-116, 2017.

[9] K. Feng, H. Qin, and L. He, An empirical research on the effect of PE on listed firms -- taking GEM list companies in China as example, Modern Finance and Economics Journal of Tianjin University of Finance and Economics, vol.04, pp. 60-69, 2013.

[10]B. Zhang, J. P. Lan, and H. X. Pang, Empirical research on the impact of PE on the value of SEMS and GEM listed companies -- based on Tobin's Q value, Macroeconomics, vol.03, pp. 1523, 2013.

[11]W. L. Megginson and K. A. Weiss, Venture capitalist certification in initial public offerings, The Journal of Finance, vol.46, pp. 879-903, 1991.

[12]P. A. Gompers, Grandstanding in the venture capital industry, Journal of Financial Economics, vol.42, pp. 133-156, 1996.

[13]C. B. Barry et al, The role of venture capital in the creation of public companies, Journal of Financial Economics, vol.27, pp. 447-471, 1990.

[14]C. P. Wu, S. N. Wu, J. Y. Cheng, and L. Wang, The role of venture capital in the investment and financing behavior of listed companies: evidence from China, Economic Research Journal, vol.01, pp. 105-160, 2012. 